\title{
Reseña a la segunda edición del libro Qué es la Geografía, 2018
}

\author{
Review of the second edition of the book What is Geography, 2018
}

\author{
Huáscar Morales \\ Universidad Mayor de San Andrés \\ huascar.hmq@gmail.com
}

\author{
Qué es la Geografía \\ Ruy Moreira \\ Editorial: Centro de Investigaciones Sociales (CIS) \\ ISBN: 978-99974-77-31-6 \\ Edición: 2018 (2da. Edición)
}

Ruy Moreira pertenece a la generación de geógrafos que renuevan el campo de estudiodesdeuna mirada críticaal capitalismo. Movimiento marcado por MiltonSantos (1926-2001), la renovación de la geografía crítica en Brasil tiene como protagonistas al profesor de la Universidad Federal Fluminense y otros renombrados autores como Carlos Walter Porto Conçalves y Rogério Haesbaert. El trabajo de Moreira durante los años 70, 80 y 90 se concentra en la relación Hombre-Naturaleza-Economía desde una perspectiva marxista para, en las décadas posteriores, continuar con reflexiones sobre una teoría general geográfica y sobre la configuración socio espacial brasilera. Trabajos como Pensar e ser em geografia (2006) o Geografia e praxis (2012) son indicativos del crecimiento del trabajo del autor desde la primera publicación de O que é geografia (1981), obra escrita apenas un año después de que el mismo dejara la presidencia de la Asociación de Geógrafos del Brasil.

La importancia de la presente obra radica, fundamentalmente, en la posibilidad de contar con un texto traducido y editado para facilitar la difusión y discusión de sus planteamientos, tributarios del marxismo. La primera edición en castellano, de abril de 2017, fue presentada en el marco del XVI Encuentro de Geógrafos de América Latina; la segunda edición se entrega apenas en julio de 2018, ambas tienen como responsable editorial al Centro de Investigaciones Sociales de la Vicepresidencia del Estado Plurinacional de Bolivia.

Inmediatamente se preguntará usted, ¿qué es realmente la geografía? Ruy Moreira, escribe su pequeño texto con la gran pretensión de resolver esta interrogante. El profesor de la Universidad Federal Fluminense entrega una obra de lo que él considera esencial en la disciplina. Qué es la geografía es un libro introductorio a la discusión geográfica que, sin perder el carácter reflexivo y crítico, conserva un lenguaje comprensible y una narrativa veloz. Siglos de pensamiento geográfico son comprimidos en pocas decenas de páginas a ritmo vertiginoso, pero con dúctil narrativa. El texto ataca 
sin preámbulos los impedimentos de las sociedades para alcanzar sus sueños de igualdad y justicia, como eje articulador. Se trata, principalmente, de una historia de la geografía contada desde las relaciones asimétricas de poder.

La obra se divide en 5 capítulos, aunque el autor alerta, más bien, sobre dos secciones bien diferenciadas. La primera mitad corresponde a una síntesis hábil y notable del proceso formativo de la geografía que hoy conocemos como disciplina académica, pero también, de esa otra noción de geografía inconexa, utilitaria y descriptiva, percibida fuera del mundo académico. La segunda mitad inicia con una provocación epistemológica que sienta las bases de los planteamientos críticos que le siguen, específicamente, marca en el centro de la discusión al espacio geográfico, para discutir cómo se ha abordado el objeto de estudio de la disciplina y qué implica esto para la relación entre los seres humanos. Si bien el hilo conductor de ambas secciones radica en las relaciones de poder, es la primera mitad la más comprensible, mientras la segunda requiere necesariamente de otro tipo de conocimientos y lenguaje que la hace menos accesible, pensando en un público amplio y diverso.

Así, en la primera sección, los apuntes históricos sobre la labor de las Sociedades Geográficas del mundo son cuestionados y explicados en clave de dominio, colonialismo e imperialismo. Narra reflexivamente los siglos coloniales y la repartición de los espacios conquistados entre las potencias de la época, recordándonos en todo momento la estrecha vinculación del saber geográfico con la conquista de un mundo en expansión. Sin embargo, esto es apenas el preámbulo para comprender el origen del conocimiento geográfico universitario-académico actual y su estratégica relación con el poder.

El autor nos conduce a través de las principales escuelas de la geografía clásica. Nos muestra los cambios sustanciales en los conceptos que dirigen a cada escuela y cómo "la geografía académica y la enseñanza que sobrevienen, heredan ese cuño pragmático de la geografía comercial, empujando el discurso geográfico y su traducción escolar hacia una visión naturalista y utilitaria" (Pg. 39). Puntualiza las reflexiones sobre el paisaje y la morfología de los alemanes, sintetiza el concepto de región de los franceses y menciona los modelos matemáticos, datos y variables de la new geography estadounidense. Según el autor, el saber general, integrado y sintético de los primeros pensadores de la geografía como Estrabón, es menos requerido por los poderes coloniales e imperiales. Por otro lado, cada vez es mayor la demanda por conocimientos muy especializados sobre culturas, recursos y pueblos en un mundo en que la geografía se hace menos necesaria.

Moreira nos indica que aquella noción de una geografía descriptiva y escolar deviene de múltiples procesos. Siguiendo con su enfoque en las relaciones de poder, el autor apunta a los intereses de quienes dirigen el conocimiento desde universidades coloniales, particularmente a la new geography y los modelos matemáticos cuyo esquema de observación vacía de contenido las relaciones entre el proceso y la forma. A pesar de aquello, la ruptura con aquella visión naturalista, matemática y básica llega con las reflexiones que el autor sintetiza de Pierre George e Yves Lacoste indicando que "la historia determina el modo de relación del hombre con su medio natural (...) lo que tenemos son hombres viviendo bajo cuadros económico-sociales que los diferencia como afortunados o hambrientos" (Pg. 40).

En general, la obra se parece a un ensayo íntimo, expresa reflexiones que se alimentan de la amplia experiencia y acumulación de conocimientos del autor. Moreira realiza la exposición de ideas como si el público lector estuviera acostumbrado a sus clases magistrales. De hecho, resulta especialmente fácil imaginarse una de sus clases al leer el contenido de la primera sección. Por otro lado, el carácter de ensayo íntimo y la condensación máxima de abultadas reflexiones sobre el espacio geográfico, pueden generar vacíos de comprensión en la segunda sección. Si bien el intento por simplificar la conceptualización de la construcción del espacio es notable, en varios pasajes se

112 | Espiral 1(1): 112 - 114 
echa de menos las referencias a otros trabajos y autores. De tal modo puede tomarse la obra como un excelente material de trabajo en aula para profesores, el que debería ser acompañado de mayores referencias y nutrido de reflexiones más extensas de lo que la obra nos ofrece. En ese sentido, la síntesis del saber geográfico presentada por Moreira está dirigida a un público que requiere un cierto dominio del lenguaje marxista para facilitar su lectura, particularmente la segunda sección, donde todas las personas interesadas y/o afines a las ciencias sociales podrán encontrar nuevas perspectivas de comprensión y producción del conocimiento.

Justamente, en la segunda sección, el autor hace énfasis en la construcción del espacio a través del trabajo humano. Es posible imaginar que las principales referencias académicas en la materia, como Harvey, Massey, Santos y principalmente Henri Lefebvre, sonríen por el esfuerzo del autor en facilitar la comprensión del proceso de construcción del espacio (la llamada naturaleza socializada), sin dejar de lado la complejidad de la interpretación dialéctica. Con el uso de lenguaje marxista, Moreira emplea toda la segunda sección para realizar su planteamiento político, a la vez que explica la relevancia del espacio geográfico en esta construcción de sociedades más (in)justas y (des)iguales.

En la segunda sección, Moreira inicia con un punteo de su crítica epistemológica. Una idea crucial en su reflexión es el papel de la percepción y su estrecha relación con la ideología y la ciencia. El autor nos facilita la comprensión de que el espacio vivido, al ser tan próximo e inmediato a todas las personas, se hace también inseparable de la facultad de percibirlo, las prácticas y saberes geográficos cotidianos son la base para decir, en consecuencia, que la geografía es un discurso teórico universal (Pg. 42). Justamente es la distancia entre la apariencia percibida del mundo y la esencia oculta en sus relaciones, lo que el autor observa desde una mirada marxista.

La obra de Moreira menciona varias etapas del desarrollo capitalista y su estrecha relación con la construcción del espacio geográfico a través del trabajo humano. Esencialmente, se describe la separación entre la naturaleza y el hombre como condición del capital para reproducirse. En ese sentido, Moreira nos explica cómo en las sociedades naturales el espacio geográfico y espacio natural son uno mismo mientras, en las sociedades históricas, el espacio geográfico es socialmente construido. Posteriormente, el capital busca separar al hombre de la naturaleza y naturalizar esa separación y, por ende, el hombre como naturaleza, también se separa de los otros hombres.

Uno de los puntos álgidos ocurre cuando el autor enfatiza que el espacio geográfico es la materialización histórica del proceso de trabajo. Es de máxima importancia la reflexión sobre esta idea, pues desde la corriente de geografía crítica, se da un tratamiento fundamental al concepto de espacio. Para el autor, el espacio geográfico es la apariencia que está íntimamente relacionada con el trabajo del hombre y el trabajo viene a ser la esencia que suele escapar a nuestra percepción. En palabras de Moreira: una vez que el proceso de trabajo implica organización, se organiza espacialmente (Pg. 59). Es así que el espacio se presenta como la expresión históricamente concreta de la transformación de la naturaleza mediante el trabajo del hombre, historia siempre correspondiente a cada sociedad que la produce y a la que, a su vez, determina.

Esta segunda sección prosigue con acápites compactos y planteamientos profundos. Espacio geográfico, espacio y sociedad, espacio y poder son subtítulos que Moreira nos ofrece, aún en el estilo de conversación íntima. Así, son dos las principales geografías presentadas y contrapuestas. Una, la de los seres humanos como naturaleza consciente de sí misma, y otra, la geografía oficial, que se encarga de separar a los seres humanos del resto de la naturaleza y, por consiguiente, de los demás seres humanos, una geografía alienante. 
La contundencia de los planteamientos del autor sobre el objeto y propósito de estudio de la geografía son inspiradores. Al afirmar que el espacio geográfico es la materialidad del proceso de trabajo y de la acumulación histórica de relaciones asimétricas de poder, Moreira nos invita a re-descubrir la geografía como campo del saber y dirigirla hacia la vida y la felicidad. La segunda sección de la obra sintetiza la complejidad del espacio y el conocimiento acumulado al respecto. El autor es claro al afirmar que el espacio no es un reflejo, no es un receptáculo y no es la base de la sociedad. Es la sociedad misma y su propia condición de existencia, espacio que determina y es determinado por la humanidad. Es este y no otro el gran salto de la geografía crítica iniciada por Lacoste y George, reflexión imposible desde una geografía naturalista, escolar y descriptiva, como indica el autor.

Ya hacia el final de la obra, el autor nos ofrece su planteamiento político más claro y nos invita a sumarnos a la acción y al estudio de la geografía desde la corriente crítica. Con la habilidad de sintetizar la historia del pensamiento geográfico y relacionar la disciplina con el ejercicio de poder, Moreira nos presenta una reflexión corta y rebosante de temas de discusión y análisis, un instrumento altamente recomendable para estudiantes de todas las ramas sociales. El autor nos invita a alejarnos decididamente del carácter utilitario del saber geográfico, emparentado con herramientas e instrumentos de trabajo que, a menudo, son confundidos con el objeto propio de la geografía.

Es el momento de adherirnos a la propuesta que el profesor Ruy Moreira nos plantea en su pequeña y contundente obra: pasar de una geografía oficial y para el capital, hacia una geografía de los seres humanos para sí mismos, pues es en la lucha social donde la geografía está más viva. 